furnishes us with no psychological differentia at all, because the attempt is made to make the distinction one of content rather than of function. But viewed simply as functional phases of the process of adjustment or coördination, the distinction has a positive value. It is preferable to substitute the term ' kinæsthetic' for the term 'motor' wherever this antithesis is not intended by the use of the latter word.

H. Heath Bawden.

\title{
DR. MEYER'S 'ELEMENTS OF A PSYCHOLOGICAL THEORY OF MELODY.'I
}

The search for the basis of music is centuries old; it antedates the search for the philosopher's stone, the Holy Grail, the North Pole; and it is not likely to be given up by the human mind until success is attained, or a reason is found for believing the search to be in vain.

The multitude of books that purport to give 'scientific laws' of music the author declares to be unsound and dogmatic; so the field being clear in the paper whose title is given in the heading Dr. Max Meyer brings out his carefully reasoned new theory; and if he seems to be dogmatic in manner we must remember that this is customary among writers on musical subjects. While the title calls for a psychological theory, the greater part of the paper covers ground belonging equally to the physicist; and I shall review it from the standpoint of the sister science.

I.

The first word to be spoken is one of cordial welcome to one who has shown himself to be an industrious worker, and willing to leave the beaten tracks. For the ultimate explanation of musical phenomena and development must be given by the psychologist; of course he must make large use of the materials furnished by the physicist, ethnologist and historian, but he must add much of his own procuring and combine all in accordance with mental laws. And the next word is one of satisfaction that the author is not ensnared by the pretty theories of the diatonic scale, which has as a matter of fact been consciously followed by only a small part of the men who have concerned themselves with music; in this opposition to the notion that the diatonic scale underlies all music he parts company with his former teacher, Professor Carl Stumpf, some at least of whose numerous writings are known to every scientific student of music.

After the introductory pages the development of the author's theory begins thus: "When we hear successively two tones the vibration rates of which are to each other as $2: 3$, or briefly speaking the tones

'Psychological Raview, May, 1900, pp. 24x-273. 
2 and 3, we notice something not describable which I shall call the relationship of these tones." "The hearer will observe something else, namely, that after hearing 2 and then 3 he wishes to go back to 2." Generally " no melody that contains 2 can end with another tone but 2." A similar relationship is observed between 2 (or powers of 2 including 1 ) and 5 and 7 and their multiples, but not between higher prime numbers, I I, I3, etc., and the lower ones. So a table is made out containing all the powers and products of these four numbers, 2 , 3,5 and 7 arranged systematically in octaves; the author says "I have found the series to suffice when continued up to ro24" and "I have found no case where higher powers of 5 and 7 are used than $5^{3}$ and 7 "; with these limitations, if the products are considered as giving vibration frequencies, the resulting scale has in the octave below ro24 d. v. 29 steps. This is the 'complete musical scale,' and it was embodied in a reed organ which gave all the notes of the table from 64 to $1024 \mathrm{~d}$. $\mathrm{v}$.

Then the author selected a few folk-songs, and several melodies dissevered from their accompaniment, of dates running from Mozart to Wagner, transposed them to the key of $\mathrm{C}$ and played them on his organ. Since there are 29 notes to the octave, there is opportunity at each point to select that one of two or three notes which produces the most satisfactory impression, so " it is in most cases very easy to determine what pitch is meant by the composer." Into the discussion of the melodies we must not go, though it is interesting to see how the author attempts to explain the tendency to progress in the melody by the hearer's constant expectation of reaching 2 ( $i, e .$, in the familiar nomenclature, the tonic) ; but this must not be reached prematurely : so on p. 267 he gives to one $C$ the value 63 instead of 64 , thus making it a comma and a quarter flatter than ordinary readers would place it. Similarly on p. 256 the unaccented passing note $F$ is called 21 instead of $211 / 3$ as would be the case in 'just intonation.' But it may be questioned whether it is legitimate to dissociate the melody from the composer's harmony in any of these cases and treat it as if it were based on a non-harmonic scale; while the analysis of folk-songs is free from this difficulty, there is the equally serious one, that the tune as written is often only an approximation to the actual one, being dependent on the prejudices and limitations of the man who noted it down.

II.

In discussing this theory we may notice first the theory in itself, and its presentation, then its relations to some older work. Unfortu- 
nately the title is not clear, and in the paper it is not made certain whether the author means to present some elements or all the elements, or whether all melody is to be thought of, or only that of Europeans : but these distinctions are important. However these may be, the theory is based on and logically developed from the statements quoted above: it is significant that these are not put in the usual form of axioms, i.e., impersonally and generically; the wording is ' we notice * * relationships'; and the 'we' in the statements about experimental work appears to be the author alone. In these statements it is the man of harmonic training who speaks; for nothing I think can be more certain historically than that these relationships have been unrecognized by most of the men throughout the ages who have concerned themselves about music. The results of such training on students of alien music I have discussed elsewhere ${ }^{1}$ and need not go into it here. The author's theory is logically developed as already stated, but only up to a certain point, where it is stopped because of a reason which does not rise above the personal plane; so the scale is not theoretically 'complete,' but at most only sufficient for present needs.

The description of the new organ, by which the theories are to be upset that were current when the music that is quoted was written, is so meager that one hesitates to draw any conclusions from the experiments performed on it: then too the relationships noticed between its sounds will almost certainly be much more marked than between the notes of voices or instruments familiar to musical composers; and a little error in tuning or difference in quality, or in the order in which the alternatives are presented to the ear (as Planck found) may determine which of two rival notes shall be chosen. And then the fact that the preferences noted appear to be those of only a single observer, whose asthetic training and sensibility however high are not stated, prevents our accepting them as valid generally, even for people of harmonic training.

The presentation of the scale would be much clearer if the values of the notes were expressed in terms of the usual piano scale. This is easily done by using the values for the author's $2,3,5$ and 7 in equally-tempered semitones, viz, octave, 12.00; fifth, 7.02 ; major third, 3.86; natural seventh, 9.69 E. S.; add these values together where the author's numbers are multiplied, casting out the twelves; e. $g ., 63=7+3^{2}$ or $9.69+7.02+7.02=23.73=11.73$ E. S., which is $0.27 \mathrm{E}$. S.flatter than the octave. The comma is 0.22 E. S.

'Science, New York, Feb. 9, 1900. 
III.

Now compare this new scale and the assumptions and conclusions associated with it with the work of former students. The Greek theorists were content to work with 2 and 3 , their products and powers. Zarlino broadened the foundations, as the author points out, by introducing 5, and therefore making more use of 6 than the Greeks did. Poole and others have insisted on adding 7. though it upsets the diatonic scale. This question of the 7 is not one of mathematical jugglery or of musical interpretation by the hearer, but simply this : did the composer mean to use at a certain point a natural seventh (written (7), having a pitch $0.3 \mathrm{I}$ E. S. below Bb in the scale of C), and score the passage for an instrument that could give it (horn, violin, etc.)? Here is one authoritative answer: Gevaert, Director of the Brussels Conservatory, says in the Annuaire of the institution for 1883 (about p. 200), that the natural seventh is used by modern composers, but not the natural eleventh or thirteenth. But admitting this, it is questionable whether the older composers quoted by Dr. Meyer had the command of this new note. On the other hand, the argument from use, which justifies admitting ( 7$)$ to the 'complete scale,' requires also the admission of many notes which the author excludes (see Gevaert's paper). Most conspicuous is the absence of the correct fourth, 4.98 E. S., i. e. the fifth taken downwards, and the notes of the series built on fourths, $\mathrm{Bb}, \mathrm{Eb}$, etc. ; his substitutes for $\mathrm{F}$ are (2I) 4.7 I E. S., and (675) 4.78 E. S. Only the most conclusive reasons can justify this outlawing of notes which almost everywhere, except in China, have belonged to the aristocracy of the scale; yet no reasons are given.

But Dr. Meyer is not alone in thus treating the scale. About twenty years ago Dr. Ivan Zoch ${ }^{x}$ was impressed with the fact that most Slavic folk-songs cannot be accompanied on the piano. This led him to study the collections of songs and the native instruments, especially the Tumbura, and finally to develop a scale therefrom. He says "The natural scale must lie in natural numbers" and "all scales in which there is a greater prime than 7 appear unmusical." So the basis is

I, $3,5,7,9,15,21,25,27,(35), 45,(63), 75,(81,105,125), 135$, etc. All melodies as actually sung he found could be correctly represented on a 12 -tone scale with the above numbers, omitting those in parentheses, divided by the power of 2 next smaller; his scale in Dr. Meyer's notation with the musical intervals added is as follows:

${ }^{1}$ Carl's Repertorium der Experimental Physik, 18, 748-764 (1882). 
$\begin{array}{lllllllllllll}2 & 135 & 9 & 75 & 5 & 21 & 45 & 3 & 25 & 27 & 7 & 15 & 2\end{array}$ 00.922 .042 .743 .864 .715 .907 .027 .729 .069 .6910 .88 12.00 E.S.

This scale was carefully laid out on monochord and a piano tuned therefrom. Into Dr. Zoch's classification of the shorter scales selected out of this we cannot enter. This attempt to find a scale in which the strange and powerful Slavic folk-songs could be expressed seemed so promising that $I$ wrote to the eminent acoustician Dr. Dvorak, of Prague, about it; his reply was the disappointing one that the theory was not proved.

Underlying these and many other studies of the scale there seems often to be an assumption that the world has but one scale and one body of musical rules, though perhaps no one expresses it so boldly except in speaking of music as ' a universal language.' It may not be amiss, therefore, to clear away any misconception by some quotations. The first is from an article $e^{1}$ on Wagner's methods : "His other innovation which is not even yet acceptable to all ears, is to employ the chromatic scale of twelve equal semitones as a basis for melody instead of the diatonic scale. The whole of the music of Tristan and Isolde would be impossible under the old laws. I need only quote one example and by no means an extreme one, of a passage impossible to sing or to listen to in anything but strictly equal temperament [quoting the duett, 'Blissful Dreams']. It is a constant wonder to me how singers trained upon diatonic scales can sing this and many still stranger passages with anything approaching bearable intonation." A little earlier than the date of this article Professor Donkin, ${ }^{2}$ of $\mathrm{Ox}$ ford, 'who was an accomplished musician and had a profound theoretical knowledge of the science of music,' and wrote on Greek music for Smith's Dictionary of Antiquities, said "The structure of modern music is founded on the possibility of educating the ear not merely to tolerate or ignore, but even in some degree to take pleasure in slight deviations from the perfection of the diatonic scale."

When we go to the study of Oriental scales the assumption of a single law is found to be positively contradicted. We know by what rules many scales have been formed, and the idea of relationship, in the sense of the author, is often if not always wanting. The principle which gives unity to the composition is something other than the harmonic relationship which tacitly underlies his numerical work. Even the demand for a close on the tonic, on which he lays so much stress (p. 257) is not commonly met with in Hindu music; though the final

1 Musical Times, London, October, 1896, p. 652.

Aconstics, Oxford, 1870, pp. 25, v. 
may be C 'accidentals' (if Dr. Meyer will pardon the word for want of a better one) have often destroyed the feeling that the tune is in the key of $\mathrm{C}$; and it is rare to find a Hindu tune that seems to ordinary musicians to end right.

\section{IV.}

In conclusion, I would like to suggest to any student who would join in this search for the basis (or the bases) of music that the greatest difficulty in the study is to get into intelligent sympathy with men of alien thought, and understand both what they did and their reason for doing it; for it is almost impossible to avoid coloring the facts by our own training and associations, or those of the observers on whom we must depend. This influence of association and habituation deserves investigation by psychologists. If the student would learn of nonharmonic scales, Mr. Ellis' papers ${ }^{1}$ detailing his and Mr. Hipkins' experiments is still the best introduction; his condensation of it for the Appendix to Helmholtz is a dry skeleton. If the student would know of the mediæval scales many papers in the Vierteljahrsschrift für Musikwissenschaft will give him light. If he would see how pugnacious and discordant the European theorists have been, and cultivate his sense for the historic elements of the problem, he should take such a bird's eye view as is given under 'Harmoniesystem' in Mendel's Musik. Lexicon; and if he would learn of the scales actually rendered by European public performers and how to train his ear for observing them, he may be commended to the admirable papers in the Vierteljahrsschrift for 1893 , by Röntgen and Dr. Planck. Of course he will soon see that in any theory of music there are two questions involved which in this brief discussion we have not discriminated as carefully as $D_{1}$. Meyer did, viz: on what principle or principles are certain notes selected to form a scale, and by what principles, physical, psychological, æsthetic, historical, etc., are these notes rearranged to form tunes.

WASHNGTON, D. C.

Charles K. Whad.

'Joumeal of The Society of Arts, London, I885. 